\section{THE INFLUENCE OF} ANNEALING TEMPERATURE ON TENSILE STRENGTH OF POLYLACTIC ACID

JIRI SUDER, ZDENKO BOBOVSKY, ZDENEK ZEMAN, JAKUB MLOTEK, MICHAL VOCETKA

VSB - Technical University of Ostrava, Department of Robotics, Ostrava, Czech Republic

DOI : 10.17973/MMSJ.2020_11_2020048

jiri.suder@vsb.cz

Polylactic acid is one of the most used materials in Additive Manufacturing technologies, especially in Fused Filament Fabrication. Although its tensile strength is relatively good in comparison with other materials in the same price category, it is possible to increase it after printing by annealing. One of the most important parameters for annealing is the annealing temperature. This article deals with experimental testing of the influence of annealing temperature on tensile strength and change of dimensions of polylactic acid samples produced by Fused Filament Fabrication. Three different variations of polylactic acid material were used for testing. The samples were annealed at $60,80,100,120,140$ and $160{ }^{\circ} \mathrm{C}$ for 30 minutes and then after gradual cooling in air, they were remeasured to determine their deformation. All the annealed samples and a set of nonannealed samples were subjected to a tensile test. Compared to the nonannealed samples, all annealed ones changed their tensile strength depending on the annealed temperature. Also, a dependence of the annealing temperature on the dimension change was found.

KEYWORDS

Annealing, Polylactic Acid, Fused Filament Fabrication, Tensile Strength, 3D print, Additive Manufacturing

\section{INTRODUCTION}

Additive technology currently plays a key role in design and manufacturing, while still evolving very rapidly [Beniak 2019, Gordeev 2018, Yao 2020]. The possibilities of applying this technology are huge, for example, the production of parts and wheels of robotic vehicles [Pastor 2020], prototypes of camera module housings [Olivka 2016], mechanical parts of racing formulas [Mesicek 2019], eye prosthesis [Sedlak 2020], bioinspired soft actuators [Hu 2020] or topological optimized parts [Jancar 2020]. One of the most commonly used Additive Manufacturing technologies is Fused Filament Fabrication (FFF), sometimes referred to as Fused Deposition Modelling (FDM) [Beniak 2020]. Both technologies are identical, only using different designations, because FDM is a registered trademark of Stratasys and other producers have to use another designation, which is FFF [Davim 2020]. FFF / FDM technologies are popular mainly due to their simplicity and low price [Beniak 2020, Yao 2020].

The materials of FFF / FDM technology are polymers and various additives that are added to them. One of the most used materials for FFF is polylactic acid (PLA) [Van der Walt 2019]. The examples of the use of PLA from FFF technology are shown in the designs of the joints in robotics arms on robotic vehicles [Pastor 2020], grippers [Epple 2020], gears [Vasilescu 2018], hopping mechanisms [Lin 2020] or snap joints [Rizescu 2020]. In the design process, it is very important to know well the properties of the material used, such as its tensile strength. Compared to other price-comparable materials, PLA has very good mechanical properties [Zakaria 2019], with a tensile strength of approximately $46 \mathrm{MPa}$ [Beniak 2019]. If it is necessary to achieve even higher tensile strength for a given print, it is possible to increase the value of strength by annealing [Bhandari 2019]. The principle of annealing is to heat the material to a certain temperature, then keep this temperature for a defined time and then to cool the material back to room temperature [Di Vona 2016]. One of the most important parameters for the annealing process is the annealing temperature. The recommended annealing temperature of the polymer to improve the mechanical properties must be greater than the glass transition temperature and less than the melting point [Bhandari 2019]. For PLA materials, the glass temperature is around $55^{\circ} \mathrm{C}$, and the melting point is around $180^{\circ} \mathrm{C}$ [Sodergard 2002]. The annealing has an effect on the molecular reorganisation, crystal thickening, coarsening, the reduction of the degree of chain folding and degree of crystallinity increases [Pastorek 2018]. That modifies the chemical and mechanical properties of the annealed material such as optical, thermal, rheological and mechanical properties, hydrolysis rate or degradation rate With the FFF / FDM method, the individual layers that have a different temperature at the time are joined together, which creates residual thermal stresses in the material [Bhandari 2019]. By annealing of printed parts, this stress decreases, which increases the resulting tensile strength. The first researches in the field of annealing of printed plastic parts produced by FFF/FDM are beginning to appear [Beniak 2019, Bhandari 2019, Koci 2019]. This article extends these works by the experimental testing of the influence of annealing temperature on tensile strength and change of dimensions of PLA samples produced by FFF. The results of this work should further help in the design of PLA printed parts.

\section{DESCRIPTION OF SAMPLES}

Three different types of PLA materials were used for testing. Classic simple PLA [Prusament 2020] without any additives, PLAPLUS [Gembird 2020], which is characterized by additives to improve its mechanical properties, and PLA-HD [Fiberlogy 2020], which is specially designed for annealing.

All samples were produced on printer Original Prusa i3 MK3S [Prusa 2020]. PrusaSlicer v2.2.0 [Prusa3D 2020] software was used to generate the G-code for the printer. The basic used printing parameters are shown in Tab 1.

\begin{tabular}{|l|l|}
\hline Parameter & Value \\
\hline Nozzle width & $0.4 \mathrm{~mm}$ \\
\hline Layer height & $0.2 \mathrm{~mm}$ \\
\hline Infill & $100 \%$ \\
\hline Number of perimeters & 2 \\
\hline Nozzle temperature & $215^{\circ} \mathrm{C}$ \\
\hline Bed temperature & $60{ }^{\circ} \mathrm{C}$ \\
\hline Perimeter speed & $45 \mathrm{~mm} / \mathrm{s}$ \\
\hline Speed for infill & $80 \mathrm{~mm} / \mathrm{s}$ \\
\hline Speed for first layer & $20 \mathrm{~mm} / \mathrm{s}$ \\
\hline Speed for top layer & $40 \mathrm{~mm} / \mathrm{s}$ \\
\hline
\end{tabular}

Table 1. The used basic printing parameters

The shape of all the samples is according to standard ISO 527-2 [ISO 527-2 2012], however, the dimensions have been adjusted to reduce the shape changes that also occur due to annealing. 
The dimensions of the samples are shown in Fig 1. Due to the small dimensions of the samples, which differ from the standard, the tensile modulus cannot be, and is not, evaluated [ISO 527-2 2012].

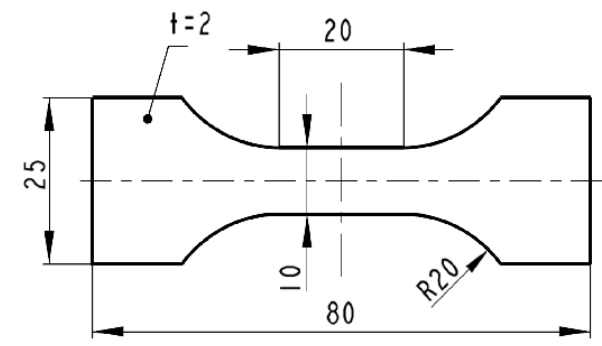

Figure 1. At the top: position of the sample on the printing bed, at the bottom: dimensions of the sample

For each material and each annealing temperature (including one reference set of samples of all 3 materials that are nonannealed), 5 samples were printed. Thus, a total of 105 samples were printed.

\section{EXPERIMENTS}

The experiments consist of two sections. Annealing and Tensile strength test.

\subsection{Annealing}

After printing, all samples were left at room temperature until they gradually cooled, then four dimensions were measured: the largest sample length, the largest width, the smallest width, and thickness. After measuring, the samples were placed in sets of 5 from each material into a Memmert Universal Oven UN30 [Memmert 2020], where they were annealed for 30 minutes at temperatures of $60,80,100,120,140$ and $160^{\circ} \mathrm{C}$.

The samples were stacked in an industrial oven on a sheet metal plate with holes. The holes allow for a subsequent visual inspection that the material did not soften too much and did not begin to flow through them. If it did, it would indicate that the temperature is too high and therefore unsuitable for annealing of that material, as the printed part would melt.

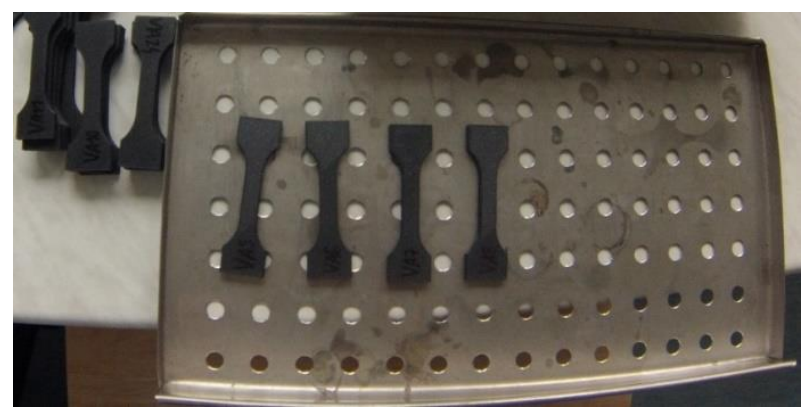

Figure 2. Sheet metal perforated plate for placing samples for annealing

After annealing, the samples were removed from the oven, where they were slowly cooled to room temperature. After cooling, the samples were remeasured, from which the amount of deformation was calculated. The subject of the measurement was only to evaluate the deformation of the stated dimensions, the change of shape was not investigated.

\subsection{Tensile strength test}

All samples were subjected to a tensile test. Testing was performed on a Testometric M500 / 50 CT machine [Testometric 2020 ] at room temperature $\left(23^{\circ} \mathrm{C}\right)$ and $50 \%$ humidity.

From the obtained data from the tensile test, the average tensile strength was evaluated.
Here it is appropriate to point out the difficulty and a certain ambiguity of determining the tensile strength of printed parts which do not have $100 \%$ filling. The tensile stress is calculated by the following equation.

$\sigma=\frac{F}{A}$

Where $\sigma$ is the stress, $\mathrm{F}$ is the force and $\mathrm{A}$ is the cross-section. Due to the fact that the cross-section changes due to the filling pattern, its determination is obscure. However, in this testing, all samples were printed with $100 \%$ infill, so it is possible to evaluate the tensile stress and find out the tensile strength. For all annealed samples, the cross-section was determined after the annealing process.

\section{RESULTS}

The results consist of two sections. Change of dimensions after annealing and Tensile strength.

\subsection{Change of dimensions after annealing}

All annealed samples showed deformations at all measured temperatures. At $160^{\circ} \mathrm{C}$, the PLA material softened so much that it flowed through a hole in a sheet metal plate on which it was placed in the oven during annealing. This behaviour was assumed, due to the melting temperature of conventional PLA, which is around $160^{\circ} \mathrm{C}$ according to the datasheet of the manufacturer [Prusament 2020]. The other two materials have a melting point of about 180 C [Fiberlogy 2020, Gembird 2020], so they resisted an annealed temperature of $160^{\circ} \mathrm{C}$ without obvious deformations. Thus the values of deformations and tensile strengths are not determined for PLA material at $160^{\circ} \mathrm{C}$. The Fig. 3 shows the flow of material through holes in sheet metal plate.

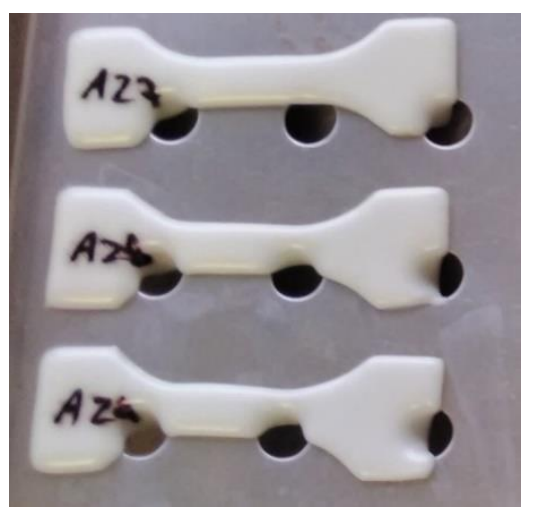

Figure 3. The melted PLA samples after annealing at $160^{\circ} \mathrm{C}$ temperature

The size of the deformations of the samples was measured in 4 dimensions shown in Fig.4.

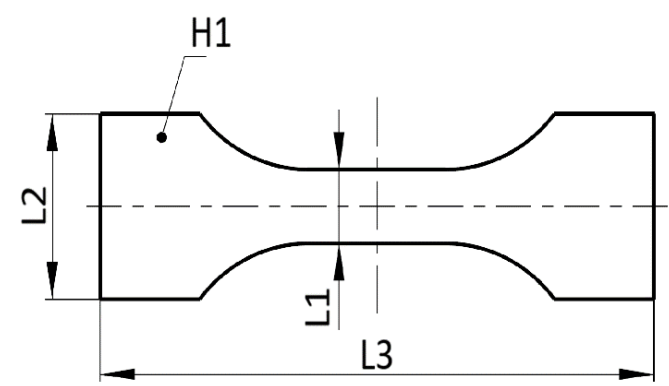

Figure 4. Measured dimensions of the sample

For all samples, thickness was increased (dimension $\mathrm{H} 1$ ), and all three remaining measured dimensions were reduced after 
annealing. Deformations of the sample's dimension are described by strain.

Tab. 2 shows the average strain of the PLA material for the individual temperature. It is evident from the values that the strain increases with increasing annealing temperature.

\begin{tabular}{c|c|c|c|c|}
$\begin{array}{c}\text { PLA } \\
\text { Annealing } \\
\text { Temperature }\end{array}$ & $\begin{array}{c}\Delta \mathrm{H} 1 \\
(\%)\end{array}$ & $\begin{array}{c}\Delta \mathrm{L} 1 \\
(\%)\end{array}$ & $\begin{array}{c}\Delta \mathrm{L} 2 \\
(\%)\end{array}$ & $\begin{array}{c}\Delta \mathrm{L} 3 \\
(\%)\end{array}$ \\
\hline $80^{\circ} \mathrm{C}$ & 7.26 & -1.91 & -3.51 & -3.10 \\
\hline $100^{\circ} \mathrm{C}$ & 12.36 & -3.64 & -5.41 & -5.59 \\
\hline $120^{\circ} \mathrm{C}$ & 13.94 & -3.98 & -6.38 & -6.58 \\
\hline $140^{\circ} \mathrm{C}$ & 15.31 & -5.26 & -7.65 & -7.68 \\
\hline
\end{tabular}

Table 2. Strain for PLA

Tab. 3 shows the average strain of the PLA-PLUS material for the individual temperature. It is evident from the values that the strain increases with increasing annealing temperature.

\begin{tabular}{|c|c|c|c|c|}
$\begin{array}{c}\text { PLA-PLUS } \\
\text { Annealing } \\
\text { Temperature }\end{array}$ & $\begin{array}{c}\Delta \mathbf{H} 1 \\
(\%)\end{array}$ & $\begin{array}{c}\Delta \mathbf{L} 1 \\
(\%)\end{array}$ & $\begin{array}{c}\Delta \mathbf{L} 2 \\
(\%)\end{array}$ & $\begin{array}{c}\Delta \mathbf{L} 3 \\
(\%)\end{array}$ \\
\hline $80^{\circ} \mathrm{C}$ & 3.80 & -0.90 & -0.63 & -0.70 \\
\hline $100^{\circ} \mathrm{C}$ & 4.16 & -1.08 & -0.66 & -0.72 \\
\hline $120^{\circ} \mathrm{C}$ & 5.09 & -1.26 & -0.66 & -0.79 \\
\hline $140^{\circ} \mathrm{C}$ & 5.19 & -1.31 & -0.86 & -0.96 \\
\hline $160^{\circ} \mathrm{C}$ & 5.66 & -1.76 & -0.79 & -1.11 \\
\hline
\end{tabular}

Table 3. Strain for PLA-PLUS

Tab. 4 shows the average strain of the PLA-HD material for the individual temperature.

\begin{tabular}{|c|c|c|c|c|}
\hline $\begin{array}{c}\text { PLA-HD } \\
\text { Annealing } \\
\text { Temperature }\end{array}$ & $\begin{array}{c}\Delta \mathbf{H 1} \\
(\%)\end{array}$ & $\begin{array}{c}\Delta \mathbf{L} 1 \\
(\%)\end{array}$ & $\begin{array}{c}\Delta \mathrm{L} 2 \\
(\%)\end{array}$ & $\begin{array}{c}\Delta \mathrm{L} 3 \\
(\%)\end{array}$ \\
\hline $80^{\circ} \mathrm{C}$ & 5.41 & -1.30 & -1.33 & -1.91 \\
\hline $100^{\circ} \mathrm{C}$ & 5.30 & -1.34 & -1.41 & -1.81 \\
\hline $120^{\circ} \mathrm{C}$ & 6.13 & -1.72 & -1.74 & -1.98 \\
\hline $140^{\circ} \mathrm{C}$ & 6.74 & -1.70 & -2.02 & -2.07 \\
\hline $160^{\circ} \mathrm{C}$ & 6.04 & -2.00 & -2.07 & -2.01 \\
\hline
\end{tabular}

Table 4. Strain for PLA-HD

For a better overview of the comparison of dimensional changes in the tested materials, the following box graphs are shown.

In fig. 5 shows the results of measuring the strain of the thickness of the sample (dimension $\mathrm{H} 1$ ). Only this dimension showed a positive value of strain, i.e. extension, compared to the nonannealed state. All other measured dimensions showed a negative value of strain, i.e. shortening. It can be seen from fig. 6 that in comparison with other tested materials, classical PLA showed the greatest strain value, while this deformation increased with increasing temperature.

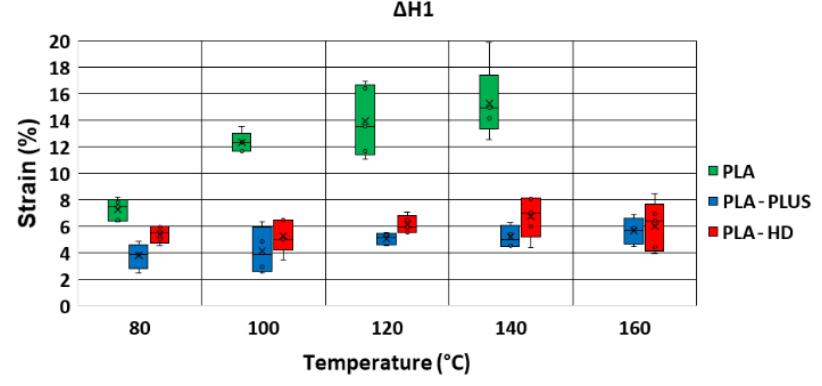

Figure 5. Strains on dimension $\mathrm{H} 1$ for measured materials

Fig. 6 shows the results of measuring the strain of the sample width L1. It can be seen that the greatest shortening of the L1 size occurred with the PLA material, while this deformation increased with increasing temperature. For other materials, this dependence is not so obvious.

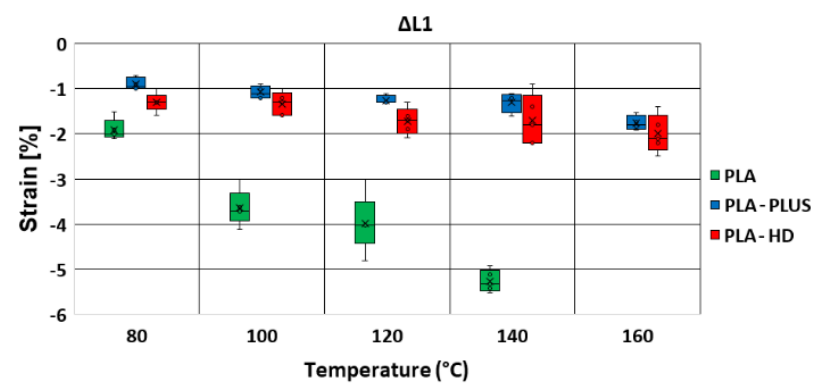

Figure 6. Strains on dimension L1 for measured materials

In fig. 7 shows the results of measuring the strain of the sample width L2.

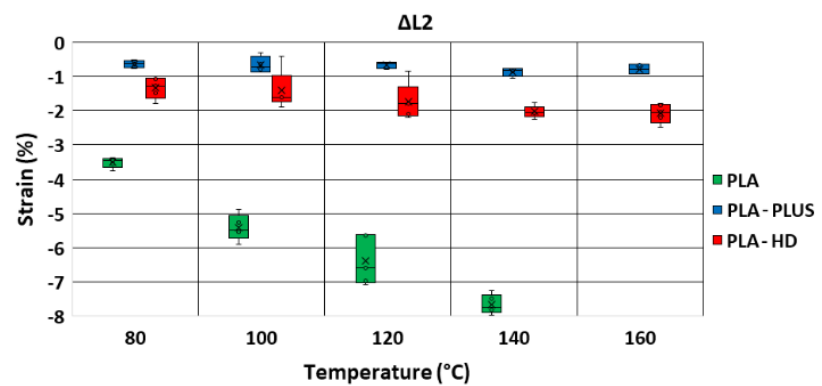

Figure 7. Strains on dimension L2 for measured materials

In fig. 8 shows the results of measuring the strain of the sample width L3.

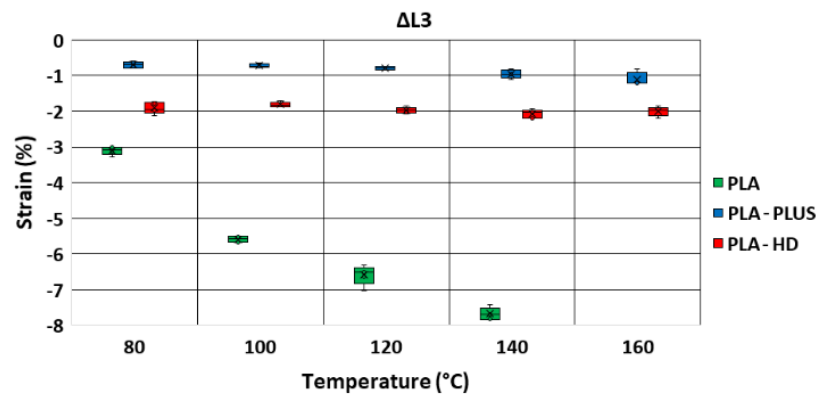

Figure 8. Strains on dimension L3 for measured materials

From fig. 5 - 8 it is evident that the greatest deformations were detected in the classic PLA material. At the same time, the dependence of the deformation on the annealing temperature is clearly visible. PLA-PLUS showed the lowest strain values and PLA-HD material slightly higher. PLA-PLUS and PLA-HD materials had smaller dependences of deformations on temperature, 
while the difference between the minimum and maximum deformation at all temperatures did not exceed $2 \%$.

\subsection{Tensile strength}

All the samples were tested in a test machine to determine the tensile strength. The percentage increase in strength is calculated relative to the nonannealed samples. All reported tensile strength values in the following figures are average, calculated from all individual samples for a given temperature and material.

Tab. 5 shows the tensile strength for PLA. The tensile strength increases with the annealing temperature. It is obvious from the results that the maximum increase in strength is at $100^{\circ} \mathrm{C}$, which is $15.16 \%$ compared to the nonannealed state. As the annealing temperature exceeds $100{ }^{\circ} \mathrm{C}$, the tensile strength begins to decrease, and its value is even lower than for nonannealed samples.

\begin{tabular}{|c|c|c|}
$\begin{array}{c}\text { PLA } \\
\text { Annealing } \\
\text { Temperature }\end{array}$ & $\begin{array}{c}\text { Tensile } \\
\text { strength } \\
(\mathrm{MPa})\end{array}$ & $\begin{array}{c}\text { Increase in } \\
\text { strength } \\
(\%)\end{array}$ \\
\hline Nonannealed & 46.43 & - \\
\hline $80^{\circ} \mathrm{C}$ & 49.50 & 6.62 \\
\hline $100^{\circ} \mathrm{C}$ & 53.47 & 15.16 \\
\hline $120^{\circ} \mathrm{C}$ & 52.50 & 13.07 \\
\hline $140^{\circ} \mathrm{C}$ & 50.94 & 9.72 \\
\hline
\end{tabular}

Table 5. Measured values for PLA

Fig. 9 shows the course of a stress-strain diagram of PLA material for individual temperatures. From all the curves for each temperature, the one whose Tensile strength was closest to the mean value was selected. From the diagram, it is evident that the strain in PLA material decreased after the annealing process.

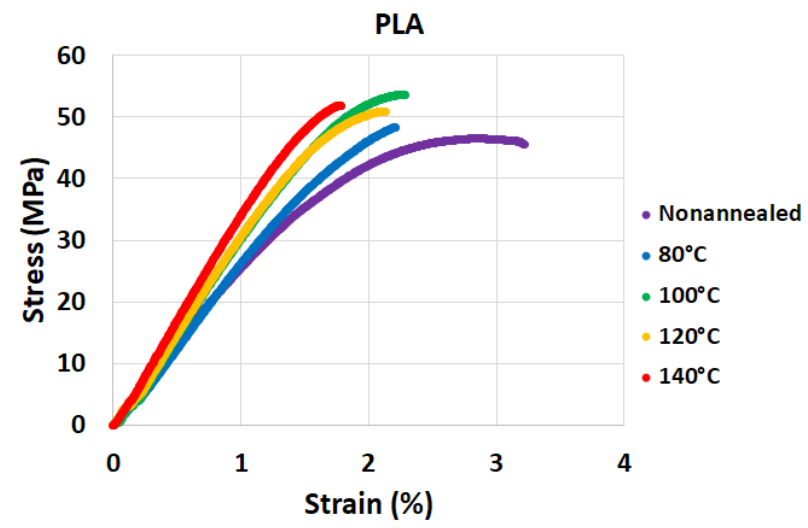

Figure 9. Stress-strain diagram for PLA

Tab. 6 shows the tensile strength for PLA-PLUS. The tensile strength changes according to the annealed temperature. It is obvious from the results that the maximum increase in strength is at $80{ }^{\circ} \mathrm{C}$ by $2.87 \%$. As the annealing temperature exceeds $80^{\circ} \mathrm{C}$, the tensile strength begins to decrease, and its value is even lower than for nonannealed samples. From the measured values, it is clear that due to a very small percentage of the average increase, it is not very appropriate to anneal the PLAPLUS material in order to increase its tensile strength.

\begin{tabular}{|c|c|c|}
\hline $\begin{array}{c}\text { PLA-PLUS } \\
\text { Annealing } \\
\text { Temperature }\end{array}$ & $\begin{array}{c}\text { Tensile } \\
\text { strength } \\
(\mathrm{MPa})\end{array}$ & $\begin{array}{c}\text { Increase in } \\
\text { strength } \\
(\%)\end{array}$ \\
\hline Nonannealed & 27.64 & - \\
\hline $80^{\circ} \mathrm{C}$ & 28.43 & 2.87 \\
\hline $100^{\circ} \mathrm{C}$ & 26.23 & -5.11 \\
\hline $120^{\circ} \mathrm{C}$ & 24.12 & -12.74 \\
\hline $140^{\circ} \mathrm{C}$ & 24.01 & -13.11 \\
\hline $160^{\circ} \mathrm{C}$ & 24.02 & -13.09 \\
\hline
\end{tabular}

Table 6. Measured values for PLA-PLUS

Fig. 10 shows the course of a stress-strain diagram of PLA-PLUS material for individual temperatures.

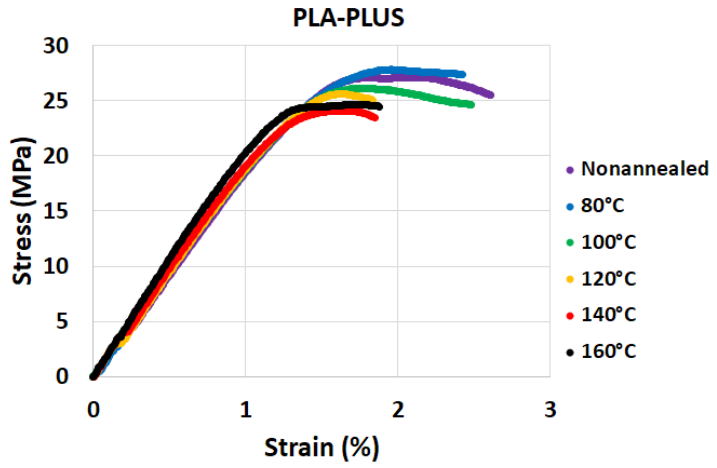

Figure 9. Stress-strain diagram for PLA-PLUS

Tab. 7 shows the tensile strength for PLA-HD. The tensile strength changes according to the annealed temperature. It is obvious from the results that the maximum increase in strength is at $80{ }^{\circ} \mathrm{C}$ by $9.62 \%$. As the annealing temperature exceeds $100{ }^{\circ} \mathrm{C}$, the tensile strength begins to decrease, and its value is even lower than for nonannealed samples.

\begin{tabular}{|c|c|c|}
\hline $\begin{array}{c}\text { PLA-HD } \\
\text { Annealing } \\
\text { Temperature }\end{array}$ & $\begin{array}{c}\text { Tensile } \\
\text { strength } \\
(\mathrm{MPa})\end{array}$ & $\begin{array}{c}\text { Increase in } \\
\text { strength } \\
(\%)\end{array}$ \\
\hline Nonannealed & 57.42 & - \\
\hline $80^{\circ} \mathrm{C}$ & 62.94 & 9.62 \\
\hline $100^{\circ} \mathrm{C}$ & 60.99 & 6.21 \\
\hline $120^{\circ} \mathrm{C}$ & 56.43 & -1.72 \\
\hline $140^{\circ} \mathrm{C}$ & 53.03 & -7.64 \\
\hline $160^{\circ} \mathrm{C}$ & 51.14 & -10.94 \\
\hline
\end{tabular}

Table 7. Measured values for PLA-HD

Fig. 10 shows the course of a stress-strain diagram of PLA-HD material for individual temperatures.

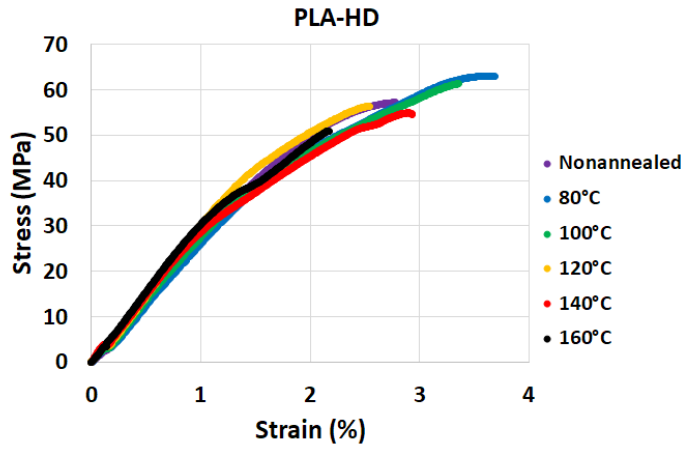

Figure 9. Stress-strain diagram for PLA-HD 
To show the variances of the individual measured voltage values, FIG. 9 shows a box fence for all annealed temperatures and materials. It is obvious that the results show significant variances for PLA, while these variations are small for PLA-PLUS.

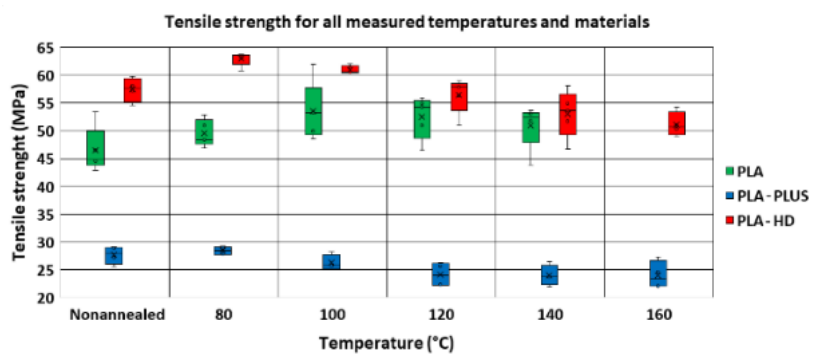

Figure 9. Box plot of tensile strength for all annealed temperatures and materials

\section{CONCLUSIONS}

Based on the measurement of selected dimensions, deformations caused by annealing were determined. The PLA material showed the highest values of deformation and showed the greatest dependence on the effect of annealing temperature on the strain. For PLA-PLUS and PLA-HD, this dependence was negligible, with PLA-PLUS showing the lowest deformation. All annealed samples were deformed depending on the position in which they were printed. The thickness of all test specimens increased (in the direction on the axis $Z$ of the FFF printer), while all other dimensions were shortened due to annealing.

The PLA-HD material showed the highest tensile strength values, on average $62.94 \mathrm{MPa}$ at an annealing temperature of $80^{\circ} \mathrm{C}$, which was on average $9.62 \%$ higher compared to nonannealed samples. The lowest tensile strength values were achieved by the PLA-PLUS material, whose highest percentage increase in strength compared to nonannealed samples was on average only $2.87 \%$ higher. It reached this value at a temperature of $80^{\circ} \mathrm{C}$, at higher temperatures its strength decreased and was even lower than in nonannealed samples. The PLA material showed the highest tensile strength values, on average 53.47 MPa at an annealing temperature of $100{ }^{\circ} \mathrm{C}$. From the measured values, it is clear that due to a very small percentage of the average increase, it is not very appropriate to anneal the PLA-PLUS material in order to increase its tensile strength. PLAHD and PLA-PLUS materials showed similar behaviour when the tensile strength began to decrease at higher temperatures, but each from a different value. Only the PLA material had higher strength values at all temperatures than in the nonannealed samples.

The results show that for the design in terms of the resulting strength is the most suitable to use PLA - HD material and anneal it to $80^{\circ} \mathrm{C}$. At this temperature, printed parts show a relatively small deformation of dimensions, which is good to take into an account while designing the parts. We recommend the adjust the printed part dimensions based on the values listed in the tables in this article. Dimensions parallel to the printing plate should be printed larger, dimensions perpendicular to this printing surface ( $Z$ axis for FFF printers) smaller than the resulting required dimensions in order to get as close as possible to the required dimensions after annealing due to the change in dimensions. To achieve the best possible accuracy, we recommend making several samples, anneal them to the required temperature, measure them, and calculate the resulting deformations, according to which the resulting dimensions of the model will be adjusted. Repeat this process until the results are satisfactory.
It should be noted that along with the change in the dimensions of the sample sizes, there was also a certain change in the shape itself. These shape changes have not been the subject of this testing, but it can be the subject of further research in the field of plastic annealing, as well as the change of the density or melting temperature.

\section{ACKNOWLEDGMENTS}

This article has been elaborated under support of the project Research Centre of Advanced Mechatronic Systems, reg. no. CZ.02.1.01/0.0/0.0/16_019/0000867 in the frame of the Operational Program Research, Development and Education. This article has been also supported by specific research project SP2020/141 and financed by the state budget of the Czech Republic.

\section{REFERENCES}

[Beniak 2019] Beniak, J., et. al. Research on parameters optimization for the Additive Manufacturing process. Transportation Research Procedia, 2019, Vol. 40, 144-149. doi: 10.1016/j.trpro.2019.07.024

[Beniak 2020] Beniak, J., et. al. Conductive material properties for fdm additive manufacturing. MM Science Journal, March 2020, pp 3846-3851, doi: 10.17973/MMSJ.2020_03_2019135

[Bhandari 2019] Bhandari, S., et. al. Enhancing the interlayer tensile strength of $3 D$ printed short carbon fiber reinforced PETG and PLA composites via annealing. Additive Manufacturing, December 2019, Vol. 30, doi: 10.1016/j.addma.2019.100922

[Davim 2020] Davim, J. P. Additive and Subtractive Manufacturing: Emergent Technologies. Walter de Gruyter GmbH, 2020. ISBN 311054816X, 9783110548167

[Di Vona 2016] Di Vona, Maria Luisa. Annealing of Polymer Membranes. Doi: 10.1007/978-3-662-44324-8_627

[Epple 2020] Epple, S \& Jung, Rolf \& Barz, Cristian \& Nasui, V. (2020). Concept for a precise academic Gripper. IOP Conference Series: Materials Science and Engineering. 749. 012030, doi: 10.1088/1757899X/749/1/012030.

[Fiberlogy 2020] Fiberlogy. Filament obtaining ABS properties after annealing. Fiberlogy, [online], 2020 [13.6.2020]. Available from https://fiberlogy.com/en/fiberlogyfilaments/filament-hd-pla/

[Gembird 2020] Gembird, PLA-PLUS filament, white, $1.75 \mathrm{~mm}, 1$ kg (3DP-PLA+1.75-02-W). [online], 2020 [13.6.2020]. Available https://gembird.com/item.aspx?id=10363

[Gordeev 2018] Gordeev, E. G., et. al. Improvement of quality of 3D printed objects by elimination of microscopic structural defects in fused deposition modeling. PLoS ONE, June 2018, doi: 10.1371/journal.pone.0198370

[Hu 2020] Hu, W., et. al. Bioinspired Three-Dimensional-Printed Helical Soft Pneumatic Actuators and Their Characterization. Soft Robotics, June 2020, Vol.7, No.3, pp 267-282, doi: 10.1089/soro.2019.0015

[ISO 527-2 2012] ISO 527-2, Plastics - Determination of tensile properties - Part 2, 2012, Second edition

[Jancar 2020] Jancar, L., et. al. Design Procedure of a Topologically Optimized Scooter Frame Part. IOP 
Symmetry 2020, 2020, Vol.13, doi: $10.3390 /$ sym 12050755

[Koci 2019] Koci, J., How to improve your 3D prints with annealing. Prusa Printers, [online], 2019 [13.6.2020], Available from https://blog.prusaprinters.org/howto-improve-your-3d-prints-with-annealing/

[Memmert 2020] Memmert. Heating \& drying ovens for laboratory \& industry. Memmert, [online], 2020 [13.6.2020]. Available from https://www.memmert.com/products/heatingdrying-ovens/universal-oven/UN30/

[Mesicek 2019] Mesicek, J., et. al. Topological optimization of the formula student bell crank. MM Science Journal, October 2019, pp 2964-2968, doi: 10.17973/MMSJ.2019_10_201893

[Lin 2020] Lin, Hongkuan \& Tekes, Ayse \& Tekes, Coskun. (2020). Design, development and modelling of single actuated, compliant and symmetrical multi link hopping mechanism. Journal of Mechanical Science and Technology. 34. 10.1007/s12206-020-0103-x.

[Olivka 2016] Olivka, P., et. al. The 3D laser range finder design for the navigation and mapping for the coal mine robot. 17th International Carpathian Control Conference (ICCC), 2016, pp 533-538, doi: 10.1109/CarpathianCC.2016.7501155

[Pastor 2020] Pastor, R., et. al. Modular Rover Design for Exploration and Analytical Tasks. Mazal J., Fagiolini A., Vasik P. (eds) Modelling and Simulation for Autonomous Systems, 2020, doi: 10.1007/978-3030-43890-6_16

[Pastorek 2018] Miroslav Pastorek \& Adriana Kovalcik (2018) Effects of thermal annealing as polymer processing step on poly(lactic acid), Materials and Manufacturing Processes, 33:15, 1674-1680, doi: 10.1080/10426914.2018.1453153

[Prusa 2020] Prusa. Original Prusa i3 MK3 3D Printer, [online], $2020 \quad$ [13.6.2020]. Available from https://shop.prusa3d.com/cs/3d-tiskarny/181-3dtiskarna-original-prusa-i3-mk3s.html\#/

[Prusament 2020] Prusament, Prusament PLA Jet Black $1 \mathrm{~kg}$ Prusa Research. [online], 2020 [13.6.2020]. Available from

https://shop.prusa3d.com/en/prusament/959prusament-pla-jet-black-1kg.html

\section{CONTACTS}

Ing. Jiri Suder

VSB - Technical University of Ostrava, Department of Robotics 17. listopadu 2172/15, Ostrava, 708 00, Czech Republic

+420 597321 209, jiri.suder@vsb.cz, www.fs.vsb.cz/354
[Prusa3D 2020] Prusa3D, PrusaSlicer - 3D Printers from Josef Prusa. [online], 2020 [13.6.2020]. Available from https://www.prusa3d.com/prusaslicer/\#_ga=2.9640 7198.300644305.15916439431493863876.1591643943

[Rizescu 2020] Rizescu, Ciprian \& Rizescu, Dana. (2020). Mechanical Behaviour Analysis of Snap Joints for Haptic Evaluation, doi:10.1007/978-3-030-539733_2.

[Sedlak 2020] Sedlak, J., et. al. Design and production of eye prosthesis using 3D printing. MM Science Journal, March 2020, pp 3806-3812, doi: 10.17973/MMSJ.2020_03_2019127

[Sodergard 2002] Sodergard, Anders \& Stolt, Mikael. (2002). Properties of Lactic Acid Based Polymers and Their Correlation with Composition. Progress in Polymer Science - PROG POLYM SCI. 27. 1123-1163, doi: 10.1016/S0079-6700(02)00012-6.

[Testometric 2020] Testometric, 50kN Machines. [online], 2020 [13.6.2020]. Available from https://www.testometric.co.uk/50kn

[Van der Walt 2019] Van der Walt, M., et. al. PLA as a suitable 3D printing thermoplastic for use in external beam radiotherapy. Australasian Physical and Engineering Sciences in Medicine, 2019, pp 1165-1176, doi: 10.1007/s13246-019-00818-6

[Vasilescu 2018] Vasilescu, M.D. \& Fleser, Traian. (2018). Influence of Technological Parameters on the Dimension of GEAR Parts Generated with PLA Matherial by FDM 3D Printing. Materiale Plastice. 55. 247-251. 10.37358/MP.18.2.5005.

[Yao 2020] Yao, T., et. al. Tensile failure strength and separation angle of FDM 3D printing PLA material: Experimental and theoretical analyses. Composites Part B: Engineering, May 2020, Vol.188, doi: 10.1016/j.compositesb.2020.107894

[Zakaria 2019] Zakaria, H., et. al. Optimization of process parameters in fused filament fabrication (FFF) utilizing poly lactic acid (PLA). IOP Conference Series: Materials Science and Engineering, November 2019, Vol.670, doi: 10.1088/1757-899X/670/1/012060 